Journal for

ImmunoTherapy of Cancer

\title{
Immune profiling of COVID-19: preliminary findings and implications for the pandemic
}

\author{
Holden T Maecker
}

To cite: Maecker HT. Immune profiling of COVID-19: preliminary findings and implications for the pandemic. Journal for ImmunoTherapy of Cancer 2021;9:e002550. doi:10.1136/jitc-2021-002550

Accepted 13 April 2021
Check for updates

(C) Author(s) (or their employer(s)) 2021. Re-use permitted under CC BY-NC. No commercial re-use. See rights and permissions. Published by BMJ.

Institute for Immunity, Transplantation, and Infection, Stanford University School of Medicine, Stanford, California, USA

Correspondence to Dr Holden T Maecker; maecker@stanford.edu

\section{ABSTRACT}

SARS-CoV-2 infection can have widely diverse clinical outcomes, from asymptomatic infection to death, with many possible clinical symptoms and syndromes. It is thus essential to understand how the virus interacts with the host immune system to bring about these varied outcomes and to inform vaccine development. We now know that both antibody and T cell responses are induced in the majority of infected individuals, and that cross-reactive responses from other coronaviruses also exist in the uninfected population. Innate immune responses are a key focus of research and may influence the course of disease and the character of subsequent adaptive responses. Finally, baseline immune profiles and changes during early acute infection may be key to predicting the course of disease. Understanding all these aspects can help to create better immune monitoring tools for COVID-19, including tools for predicting disease severity or specific sequelae, perhaps even prior to infection.

\section{INTRODUCTION}

SARS-CoV-2 can cause asymptomatic infection in some individuals, mild-to-moderate self-resolving symptoms in others and severe manifestations like acute respiratory distress syndrome (ARDS), coagulation disorders and death in smaller subsets of patients. $^{1-3}$ The range of symptoms is highly variable and can include many different organs and systems. ${ }^{4}$ In addition, some individuals experience prolonged symptoms, if not prolonged viremia, a phenomenon often referred to as 'long COVID-19' or 'postacute COVID-19'.5 Among children, a small proportion develop a multiorgan inflammatory syndrome (MIS-C), ${ }^{6} 7$ usually after resolution of viral infection. While clinical factors such as age and pre-existing conditions like obesity and diabetes are known to increase the risk of severe disease ${ }^{89}$ there is an inability to accurately predict who is at greatest risk, and who will experience particular symptoms or sequelae.

Variation in the spectrum of COVID-19 disease could potentially derive from viral variation, which is increasingly being described. ${ }^{10} 11$ However, it is not yet clear if emerging mutant virus strains cause increased disease severity, or simply increased transmissibility. There can certainly be a contribution of host genetic factors, including some related to viral binding and entry. ${ }^{12-14}$ But genetic variation in the immune response has also been implicated, including recently discovered variants in type I IFN immunity associated with severe disease. ${ }^{15}$ In fact, variability in the host immune response is likely to play a major role in determining the course of SARS-CoV-2 infection, as exemplified in figure 1 and discussed in detail here. Given this, there is a need to apply immune profiling to better understand the interaction of this virus with the human immune system and how this influences clinical outcomes and informs vaccine development.

While other papers in this review series will address the interaction of cancer and COVID-19, this review will provide an overview of COVID-19 immune profiling in general. Immune profiling is usually divided into humoral or serology assays, which measure antibody responses and soluble factors such as cytokines; and cellular assays, which assess global as well as antigen-specific immune cells (figure 2). These latter assays can profile cells of the innate and/or adaptive immune system. All of these immune responses are relevant to COVID-19, so while they are reviewed individually here, a comprehensive approach will be most informative. For each type of immune finding, one or a few key references are provided, since the literature is already so vast as to preclude citing all relevant papers in this field. In addition, this review is focused mostly on immune responses as measured in blood; but valuable observations (discriminating 


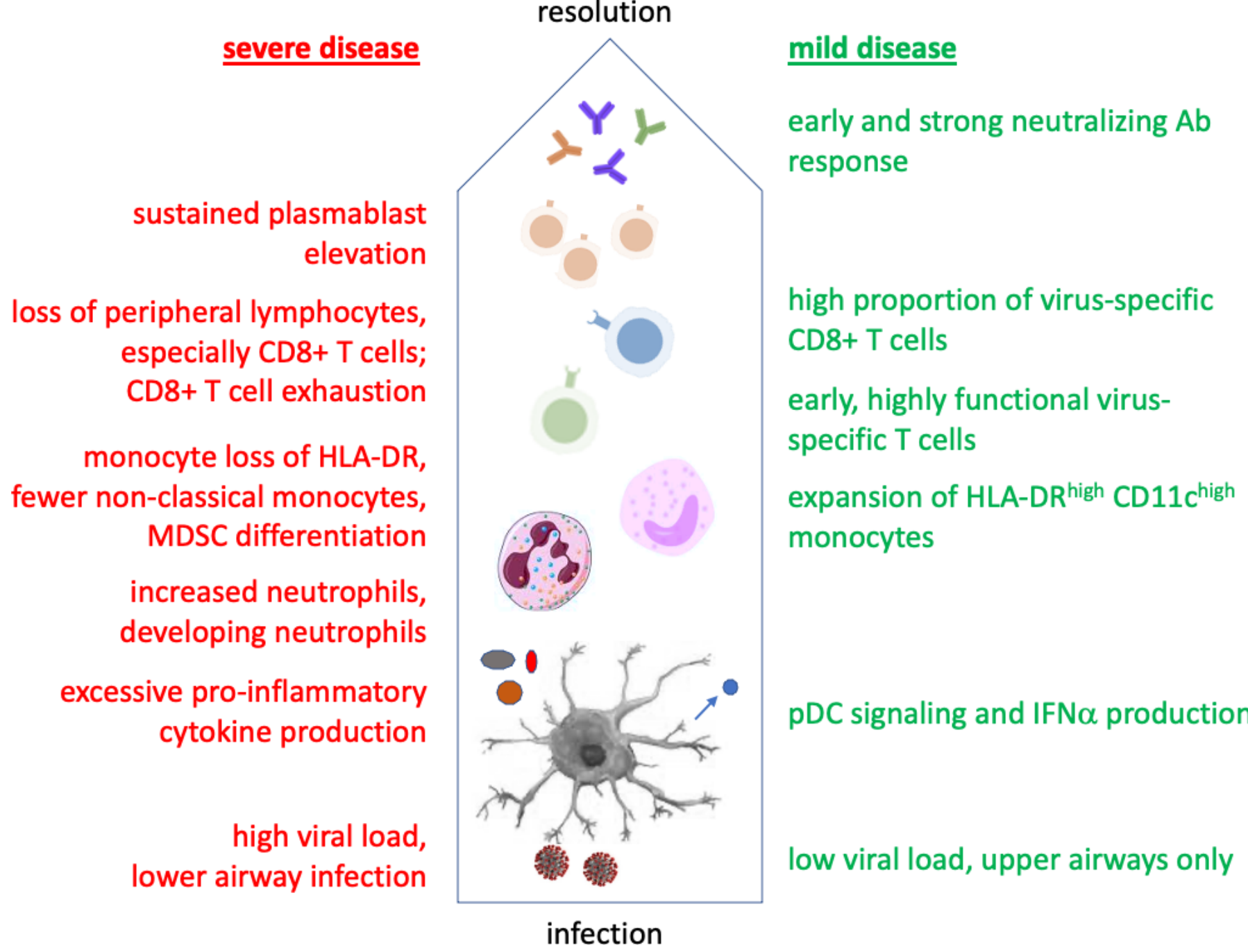

Figure 1 Immunological course of mild versus severe COVID-19. Cells and secreted proteins involved in the immune response are depicted from the bottom up, beginning with viral interactions with antigen-presenting cells such as DCs. Findings in green versus red have been associated with mild versus severe disease, respectively. DCs, dendritic cells; MDSC, myeloid-derived suppressor cells; pDC, plasmacytoid.

COVID-19 severity levels, eg) can be made from singlecell studies of tissues such as lung, or fluids such as bronchoalveolar lavage, when available. ${ }^{16} 17$

\section{Serology: antibodies}

Antibody responses are the most-studied aspect of the immune system, and have certainly been well characterized in COVID-19. ${ }^{18}$ They can be measured by ELISA as well as by multiplexed immunoassays, using bead-based fluorescent or microtiter plate electrochemiluminescence readouts. Even higher multiplexing can be achieved with protein/peptide microarrays. ${ }^{19} 20$ Neutralization capacity can be measured by infectivity assays, for which lentiviral pseudoparticles expressing SARS-CoV-2 spike protein have been employed to reduce biohazard risks. ${ }^{21}$

Most infected individuals raise a detectable antibody response to SARS-CoV-2, including IgM, IgG, and IgA antibodies to the spike protein and its receptor-binding domain. ${ }^{1822}$ These responses tend to be higher in more severe cases, though there is considerable population heterogeneity. Antibody levels generally peak within 2 weeks for IgM and 3 weeks for $\operatorname{IgG},{ }^{23}$ for both nucleocapsid and spike protein targets. These responses are relatively stable for at least 8 months or more, though the degree of decline has been debated. While one large Islandic study ${ }^{24}$ and another even larger New York study ${ }^{25}$ reported antibodies 'do not decline' and 'persist' over several months, other (smaller) studies showed a slow decay in titers, ${ }^{26} 27$ with one study showing a median decrease of $34.8 \%$ over 3 months. ${ }^{26}$ These observations were also more or less corroborated by a preprint describing a very large UK cohort, where a mean decrease of $26.5 \%$ over 3 months was observed. ${ }^{28}$ This decline was age-dependent, with larger decreases in the elderly. Another healthcare worker study reported that $91 \%$ of seropositive individuals remained seropositive over 3-5 months, which is in keeping with generally small declines over this period. ${ }^{29}$ A good correlation between total and neutralizing IgG antibodies has also been reported. ${ }^{26}$ 


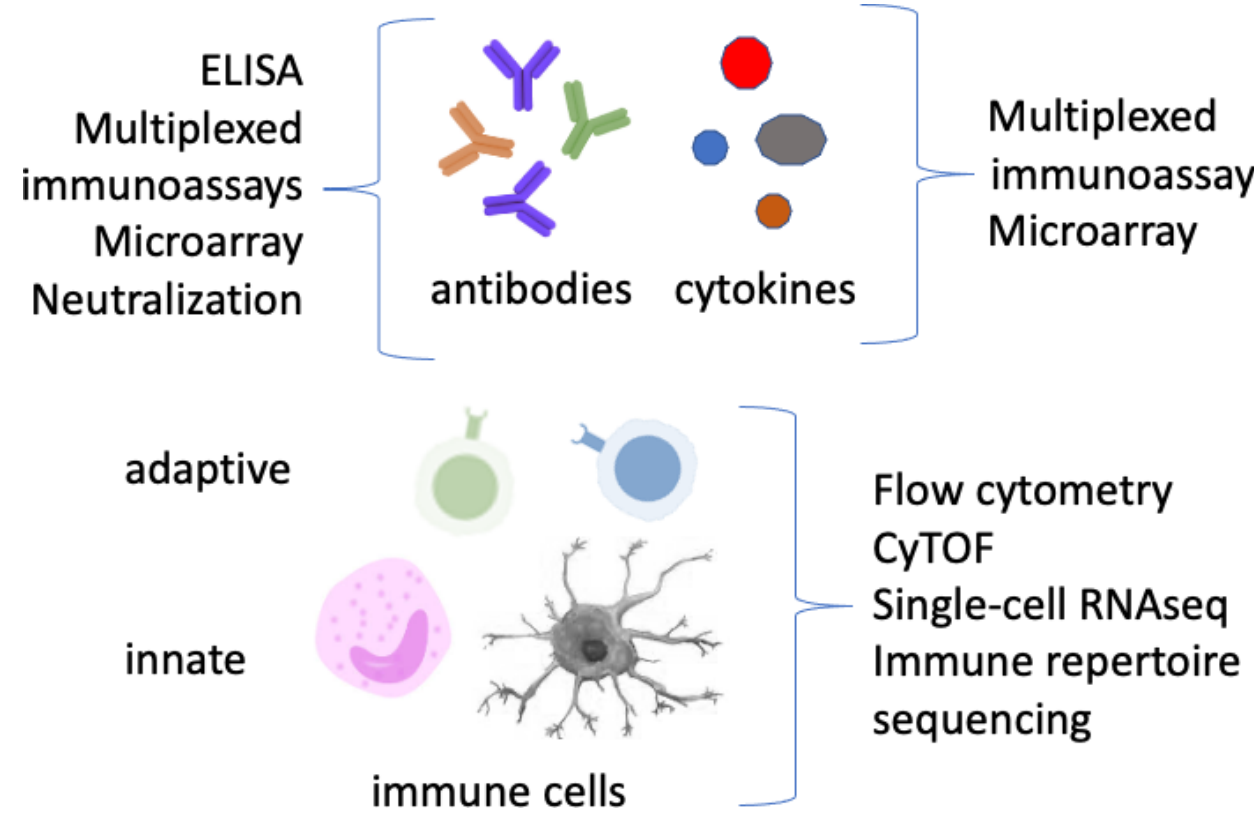

Figure 2 Immunological biomarkers and common assay platforms employed to detect them. Techniques listed are not meant to be exhaustive.

Interestingly, memory B cells seem to persist or increase even as antibody levels wane. ${ }^{30} 31$ Also, Gaebler et $a l^{32}$ showed that memory B cells not only persist, but undergo somatic hypermutation over the course of 6 months, consistent with persistent antigen.

What is less certain is whether protection against COVID-19 is durable in a time frame of years, given that protection against other circulating coronaviruses tends to be short lived, as seen by increased reinfection after 1 year. ${ }^{33}$ This could be due to waning antibody titers, particularly neutralizing antibodies, and/or declining $\mathrm{T}$ cell responses, the latter to be discussed further on in this review. Interestingly, germinal centers are significantly blocked in COVID-19, which might affect antibody quality and durability. ${ }^{34}$ Nevertheless, somatic hypermutation of antiviral antibodies still occurs. ${ }^{30} 32$ Cagigi et $a l^{35}$ also found that airway antibodies tend to wane quickly, despite persistent serum IgG in patients with COVID-19.

All these studies prompt questions about the durability of vaccine responses, as COVID-19 vaccines are now being distributed at an unprecedented rate. Fortunately, the data to date show no drastic decline in antibody titers to day 119 in recipients of an mRNA vaccine. ${ }^{36}$ Whether an annual 'booster' will be needed is still debated, but it's likely that circulation of new variants will drive this need at least as much if not more than waning antibody titers.

Despite the short-lived protection against seasonal coronaviruses, many people (especially children) harbor antibodies to one or more of these, and such antibodies can be cross-reactive with SARS-CoV-2. ${ }^{19} 2237$ This could account for some of the decreased COVID-19 severity generally seen in children. However, children (like adults with mild or asymptomatic disease) tend to produce lower antibody responses to SARS-CoV-2 once infected. ${ }^{38}$
Mapping the protein or even epitope specificity of antibody responses could provide potential correlates of protection or disease severity. One report showed nucleocapsid-specific IgG to be significantly higher in intensive-care unit (ICU) versus non-ICU patients, while spike-specific IgG was higher in non-ICU patients. ${ }^{23}$ The combination of nucleocapsid-specific and spike-specific antibody detection was also helpful in identifying more infected patients ( $75 \%$ with the combination).

Some studies have speculated on the value of serology against heterologous antigens in the context of COVID19. Vaccines such as diphtheria-tetanus-pertussis share some cross-reactive B cell epitopes with SARS-CoV2, ${ }^{39}$ which could offer a level of cross-protection in children; but this idea is so far untested. CMV infection could contribute to immunosenescence and the general severity of COVID-19 in the elderly, ${ }^{40}$ though this too is speculative. For influenza, there is little epitope cross-reactivity with SARS-CoV-2 ${ }^{39}$ though there is one report showing a reduced incidence of COVID-19 respiratory symptoms in pediatric patients vaccinated for influenza versus those not vaccinated. ${ }^{41}$ Of course, this could also be due to confounders not controlled for in the study.

From these observations, we can derive recommendations for prospective studies to employ a comprehensive serology assessment. This should include multiple proteins/epitopes of SARS-CoV-2, to maximize identification of seropositives and potentially detect differences between severity groups. Inclusion of heterologous antigens, such as those from seasonal coronaviruses, could also be informative.

\section{Serology: cytokines and other soluble mediators}

Cytokines are important signaling molecules of the immune response, and their elevation in blood or in 
nasal swabs or aspirates may be predictive and/or correlative with the course of disease. Platforms for measuring soluble cytokines have evolved from traditional ELISA to multiplexed platforms such as fluorescent bead-based assays, electrochemiluminescence assays, or microarrays. Proximity extension assay (PEA) can also be used for multiplexed readout of cytokines and other soluble proteins. PEA employs pairs of DNA-tagged antibodies to generate a polymerase chain reaction (PCR) product that is read out by quantitative PCR (qPCR). This technology provides very high multiplexing with good specificity, ${ }^{42}$ and is being used in large COVID-19 clinical studies such as IMPACC (https://www.niaid.nih.gov/clinicaltrials/immunophenotyping-assessment-covid-19-cohortimpacc). It has also been used extensively in systems-level COVID-19 studies such as $\mathrm{Su}$ et al. ${ }^{43}$ An even greater level of multiplexing has been achieved with aptamerbased assays, which have also been used to identify host proteins, many of them associated with a genetic variation that interact with or are involved in a maladaptive response to SARS-CoV-2. ${ }^{44}$

A key feature of severe COVID-19-associated ARDS is the high level of many proinflammatory cytokines in serum, a so-called 'cytokine storm ${ }^{45}$ While controlling these cytokines has been thought by many to be important, ${ }^{46}$ there is controversy about the relevance of these cytokines to disease pathology, and whether the 'storm' is even as severe as in other syndromes like sepsis-related ARDS. ${ }^{47} 48$ Nevertheless, it is clear that serum cytokine levels are a predictor of disease severity, including interleukin (IL)-6, IL-8, and tumor necrosis factor (TNF) ${ }^{49}$ and growth/ differentiation factor-15 (GDF-15). ${ }^{50}$ Serum levels of TNSF14 (LIGHT), EN-RAGE (an inflammatory cytokine associated with coronary heart disease), and oncostatin-M (an IL-6 family member) have also been correlated with disease severity. ${ }^{51}$ Clinically, studies have targeted granulocyte/macrophage-colony stimulating factor (GMCSF) ${ }^{5253}$ and IL- $1^{54}$ with monoclonal antibodies and seen clinical benefit in patients with severe COVID-19 and ARDS. Zhao et al have also shown that high levels of serum GM-CSF and IL-17A correlated with more severe disease, and were linked to lung-resident Th17 cells. ${ }^{55}$ While all of these can be considered proinflammatory cytokines, together they represent a similar but not necessarily identical set of cytokines compared with those elevated in sepsis and other respiratory illnesses.

Other soluble protein biomarkers have also been identified as elevated in COVID-19. These include long pentraxin 3, expressed by monocytes and endothelial cells, and whose plasma level was found to be predictive of mortality in hospitalized patients with COVID-19. ${ }^{56}$ Similarly, plasma levels of calprotectin, together with non-classical monocyte frequencies, could be predictive of those who develop severe COVID-19. ${ }^{57} 58$ In fact, a signature of multiple soluble biomarkers is probably ideal for predicting disease course. Abers $e t a \tilde{l}^{9}$ described a set of 12 soluble proteins, including various cytokines, whose initial level on hospital admission was predictive of mortality. Four of these (sTNFRSF1A, sST2, IL-15, and IL-10) longitudinally separated survivors throughout the course of hospitalization.

Given the somewhat eclectic list of cytokines associated with COVID-19 severity, there is as of yet no single panel that uniquely covers all of these. Rather, most groups continue to use highly multiplexed research platforms. Alternatively, a simple real-time readout of a few key predictive cytokines could be used for early patient assessment, as was done by Del Valle $e t a t^{49}$ using a commercial point-of-care immunoassay system.

\section{Cellular immune monitoring}

Cellular immunity is inherently more complex to analyze, but new technologies have broadened our ability to do complex immunophenotyping at the single-cell level. Standardized immunophenotyping panels have been described for high-parameter flow cytometry ${ }^{60}$ and Cytometry by Time of Flight (CyTOF) mass cytometry. ${ }^{6162}$ Many studies also use single-cell transcriptomics, which can be adapted to include staining with DNA-tagged antibodies (AbSeq or CITE-seq) ${ }^{63}$ as well as targeting of rearranged T cell receptor (TCR) and Ig genes. This obviously creates a powerful, unbiased approach for single cell phenotyping, but one which still suffers from issues of high cost and low throughput, as well as analytical complexity. Another single-cell technology, employing microwell-based cytokine detection to quantify the 'secretome' of up to 32 cytokines secreted by activated T cells, has also been used in multiomics studies to distinguish mild from moderate or severe COVID-19. ${ }^{43}$

\section{Innate cellular immunity}

Recent years have seen a greater appreciation for the key role of innate immune cells, which encompass granulocytes (neutrophils, eosinophils, and basophils), monocytes and macrophages; dendritic cells (myeloid and plasmacytoid (pDCs)); and innate lymphoid cells (ILCs, which include natural killer (NK) cells). While these cells do not have antigen-specific receptors, they can in some cases develop a heightened responsiveness, or so-called 'trained immunity' to certain pathogens. ${ }^{64}$ And, of course, the innate response triggers, and its character helps determine, the magnitude and quality of the ensuing adaptive response.

Trained immunity, including that induced by the tuberculosis vaccine $\mathrm{BCG}^{65}$ may influence the susceptibility of different populations to COVID-19 and/or to severe disease. ${ }^{66}$ Such differences in innate immunity may underlie geographical differences in overall severity of COVID-19 and could be part of the protection from severe disease generally seen in children.

Among patients with COVID-19, a major phenotypic finding of innate immune cells is the down-regulation of human leukocyte antigen-DR isotype (HLA-DR) on monocytes, which appears to correlate with severity. ${ }^{51} 576768$ This could be related to early virus-induced type I IFN signaling, which has been a subject of study in COVID-19 
and influenza. ${ }^{69}$ In severe COVID-19 cases, decreased IFN $\alpha$ production and reduced mTOR signaling in pDCs has been described. ${ }^{51}$ This is reinforced by the frequent finding of inborn errors of type I IFN signaling ${ }^{15}$ or autoantibodies to type I IFN ${ }^{70}$ in patients with severe COVID19. Interestingly, the German DeCOI consortium found an increase in HLA-DR ${ }^{\text {high }}$ CD11 $c^{\text {high }}$ monocytes with a strong IFN-stimulated gene signature in patients with mild COVID-19. ${ }^{67}$ In severe cases, these cells were absent, and the authors instead observed HLA-DR ${ }^{\text {low }}$ monocytes. A recent study also found myeloid-derived suppressor cells (MDSCs) in the circulation (but not airways) of patients with COVID-19, in a severity-dependent manner. ${ }^{71}$ In fact, many studies have reported a range of changes across the myeloid compartment in COVID-19. ${ }^{515767687273}$

Neutrophils are also affected in severe COVID-19, as a result of emergency hematopoiesis generating circulating neutrophil precursors, or developing neutrophils, ${ }^{67} 74$ which have a unique gene expression profile that is similar to that of plasmablasts. ${ }^{74}$

NK cells are activated in COVID-19 as well, and distinct immunotypes of NK cells can be linked with disease severity. ${ }^{75}$ Additionally, mucosal-associated invariant $\mathrm{T}$ cells (MAIT cells), an innate-like T cell population, have been shown to both decrease in number and show an activated phenotype but impaired function in patients with COVID-19. ${ }^{767}$ Interestingly, the level of HLA-DR expression on MAIT cells was found to correlate with a disease severity score. ${ }^{76}$

\section{Adaptive cellular immunity}

Adaptive immune responses are those elaborated by B and $\mathrm{T}$ cells, which uniquely expand clones of memory cells with receptors (Ig and TCR) specific for pathogen epitopes. Bulk or single cell sequencing of those receptors allows the identification of expanded clones. The antigenic specificity of those clones remains difficult to infer, though computational methods for this have been developed. ${ }^{78} \mathrm{~T}$ cell specificity can also be screened by stimulation with peptides, often using overlapping peptide pools, which can be deconvoluted to determine individual peptide reactivity. The responses are generally read out by flow cytometry (with intracellular cytokine and/or activation marker staining), or by ELISpot assays, which measure single-cell cytokine secretion in a 96-well plate format. Interestingly, T cell responses in unexposed individuals were preferentially seen with overnight, rather than longer $(6 \mathrm{~d})$ stimulation, ${ }^{79}$ highlighting the importance of assay conditions in these types of experiments.

SARS-CoV-2 infection results in detectable $\mathrm{B}$ and $\mathrm{T}$ cell responses in the vast majority of cases, with generally robust responses in mild infection. ${ }^{3780-88}$ T cell responses have even been described in close contacts of infected individuals, in the absence of detectable viral infection. ${ }^{89}$ It is not yet clear whether differences in protein targets and epitope specificity may be associated with severity; however, children tend to have lower magnitude responses to spike protein, despite their relative lack of severe disease. ${ }^{90}$ Grifoni et $a l^{84}$ showed that $70 \%$ of convalescent patients had CD4+ Tcell responses, while $100 \%$ had CD8 + T cell responses to SARS-CoV-2, ${ }^{84}$ using predicted epitope peptide pools. These were further mapped to show a wide breadth of protein target specificities. Peng et $a l^{80}$ further showed that mild cases had higher proportions of virus-specific CD8 $+\mathrm{T}$ cells.

Recently, Tan et a ${ }^{91}$ showed that early induction of IFN $\gamma$-producing $\mathrm{T}$ cells responding to SARS-CoV-2 proteins was associated with viral clearance and milder disease. Thus, the kinetics of $\mathrm{T}$ cell responses could be important in disease course, and early measurement could help predict severity.

The clonal distribution of the $\mathrm{T}$ and $\mathrm{B}$ cell responses to SARS-CoV-2 may also play a role in determining disease course. Schultheiß et a $\ell^{22}$ have created a public database of over $14000000 \mathrm{~B}$ cell receptor and TCR sequences from the blood of acute and convalescent patients with COVID-19. TCR clonality and skewing were associated with flow cytometric findings of $\mathrm{T}$ cell activation phenotypes and interferon responses. Certain TCR clones were exclusively associated with recovery. Cheng et a $t^{3}$ have also studied TCR clonal expansions in adult patients with COVID-19 with hyperinflammation, and find TCR skewing that may result from superantigen-like interactions of the SARS-CoV-2 spike protein with MHC class II.

Multiple studies have also characterized T cell phenotypes and functions in the context of COVID-19..$^{378081858794}$ These tend to show a robust and highly functional $\mathrm{T}$ cell response, with a Th1 phenotype and good proliferative potential, following mild to moderate disease ${ }^{85} 87$ While severe disease can be associated with a higher proportion of SARS-CoV-2-specific T cells, ${ }^{80}$ they may have a more exhausted phenotype, ${ }^{82}$ with less functionality and a lower IFN $\gamma / \mathrm{TNF} \alpha$ ratio compared with influenza-specific T cells.

As with antibodies, $\mathrm{T}$ cell responses can be cross-reactive with other common coronaviruses. This can be seen in the form of SARS-CoV-2-reactive T cells in the blood of uninfected individuals. ${ }^{30} 37848594$ These cells tend to have lower avidity for SARS-CoV-2, but likely correspond to a predisposition toward milder disease should these individuals become exposed to SARS-CoV-2.

Additionally, Paschold et a ${ }^{75}$ found IgH gene rearrangements associated with SARS-CoV-2 reactivity in the repertoire of prepandemic individuals' B cells. These were of particular interest, as they were decreased in individuals over 60 years old and in those with cancer-potentially accounting for some increased risk of severe COVID-19 in these groups.

\section{Broad immunophenotyping}

While studies of antigen-specific T and B cells can be highly informative, these are rare populations and assays to identify them are more complex than simple immunophenotyping assays. But important information can also lie in the proportions and phenotypes of broader cell populations. This includes total lymphocytes, which tend to decrease in 
COVID-19, with the degree of decrease predicting disease severity. ${ }^{96-98}$ Since neutrophils, conversely, increase with disease severity, the neutrophil-to-lymphocyte ratio may be predictive as well. ${ }^{68}{ }^{96}$ Reactive lymphocytes can also be identified by hematology analyzers, and were found to be lower in COVID-19 relative to other viral infections. ${ }^{99}$ Finally, NK cell, monocyte, and DC frequencies can be reduced in acute COVID-19. ${ }^{100}$

Within the lymphoid compartment, suppression of total CD3+ $\mathrm{T}$ cells, and particularly CD8+ T cells, has been shown to predict severe disease. ${ }^{101}$ Furthermore, a highly differentiated and/or exhausted CD8 +Tcell compartment, which can result from long-term CMV infection, may predispose to worse COVID-19 outcome. $^{40102103}$ Mazzoni et al ${ }^{104}$ found that polyclonal $\mathrm{T}$ cell activation revealed decreased cytokine production along with terminal differentiation in patients with COVID-19 generally. They also found reduced NK cell granzyme B expression in ICU patients specifically. Interestingly, the latter was correlated to serum IL-6 levels and was reversed by tocilizumab (anti-IL-6) therapy.

$\mathrm{B}$ cell subsets and plasmablasts may also be correlated with severe COVID-19. ${ }^{105} 106$ Specifically, there is an inverse relationship between the frequency of memory $B$ cell subsets and symptom duration in recovered individuals. ${ }^{106}$ However, Bernardes et $a l^{105}$ found proliferating, metabolically active plasmablasts to be increased in severe disease, along with circulating megakaryocytes and increased erythropoiesis.

Many other studies have observed changes in frequency or phenotype of other specific immune cell populations, too numerous to review in detail here. As an example, Kulkarni-Munje et $a l^{107}$ noted a progressive decrease in pDCs and an increase of IFN $\gamma$-producing NK cells in severe disease relative to mild disease and healthy controls, while CD16 +monocytes trended higher in both mild and severe cases relative to controls. However, this latter finding may be due to increases in intermediate (CD14+CD16+) monocytes, as the frequency of nonclassical $\left(\mathrm{CD} 14^{\text {low }} \mathrm{CD} 16+\right)$ monocytes has been found to decrease with severe disease ${ }^{57}$ Kulkarni-Munje et $a l^{107}$ also found an increase in activated (HLA-DR+, CD38+) CD8 +T cells along with IL-2-procucing $\mathrm{CD} 4+\mathrm{T}$ cells and $\mathrm{CD} 4+$ $\mathrm{T}$ follicular helper cells in severe relative to mild disease. These latter could be identified by both CXCR5 and PD-1 expression.

The complexity and dynamic nature of the immune response makes it difficult to find a single cellular parameter that stably and unequivocally predicts disease course. In fact, patients are heterogeneous, and the time of sampling is important for many markers. Some, like lymphocyte and CD8+ T cell count, are relatively early and relatively consistent predictors, while others may be useful only in subsets of patients. Mathew et al ${ }^{108}$ identified 'immunotypes' of patients with COVID-19 based on different key features (like $\mathrm{T}$ cell activation and plasmablast levels) and their immune trajectories. Three of these immunotypes were linked to poor outcomes.
Similarly, Lucas et $a l^{109}$ identified early immune signatures, including elevated cytokines and a progressive type 2 response (IL-5, IL-13, eosinophils, and IgE) that corresponded to a severe disease course. Rodriguez et $a l^{10}$ describe similar longitudinal changes including basophil and eosinophil increases in a longitudinal analysis of 39 severe patients with COVID-19. Single-cell sequencing to define longitudinal immune trajectories has also been done to compare COVID-19 with influenza. ${ }^{111}$ This study found distinct signaling pathways, including STAT1 and IRF3, active in COVID-19, with STAT3 and NFKB signaling active in influenza. Interestingly, both diseases showed increased IL-6 concentration, but patients with COVID-19 had a relative increase of IL-6 receptor gene expression in T cells and DCs. Finally, one of the most comprehensive longitudinal, multi-omic studies of COVID-19 was performed by $\mathrm{Su}$ et $a t^{43}$ who integrated plasma proteomics and metabolomics, PBMC transcriptomics, PBMC phenotyping, immune receptor repertoire sequencing, single-cell secretome, and electronic health record data. They describe an immunological shift between mild and moderate/severe cases, characterized by increased inflammation, decreased blood nutrients, and changes in immune cell populations. These latter include some of those described in other studies above, such as HLA$\mathrm{DR}^{\text {low }}$ monocytes, exhausted CD4+ and CD8+T cells, and cytotoxic CD4+ T cells.

From all the above, it is obvious that there are numerous changes in COVID-19 in both antigen-specific and global populations of many immune cell subsets. Some of the simplest and broadest changes are actually reasonably good at predicting disease severity, including total lymphocyte and CD8 + T cell counts (both lower in severe cases), or neutrophil-to-lymphocyte ratio (higher in severe cases). These measurements can be made from a complete blood cell (CBC) test or (for CD8+ T cells) by clinical flow cytometry panels (BTNK assays). As such, these can already be implemented into clinical decision making.

More sophisticated measurements require more detailed multiparameter flow cytometry or CyTOF panels, including activation and differentiation markers for multiple cell types. These panels may also include activation with specific SARS-CoV-2 antigens (often overlapping peptide pools) to read out antigen-specific $\mathrm{T}$ cells; or global activation, for example, with phorbol myristate acetate +ionomycin, to read out global immune competence. ${ }^{112}$ Even higher information content can be achieved with single-cell transcriptomics, frequently in combination with TCR or Ig repertoire targeting and/ or protein targeting with nucleic acid-tagged antibodies (AbSeq or CITE-seq). But these technologies are most practical for initial pilot investigations. Larger follow-up studies can then employ targeted flow or CyTOF panels with the most interesting markers gleaned from singlecell transcriptomics. 


\section{Other clinical monitoring tests}

Other clinical markers that are potentially useful along with monitoring of immune cells, antibodies, and cytokines, include markers of inflammation and tissue injury, such as $\mathrm{C}$ reactive protein (CRP), procalcitonin, or cardiac troponin. Tan et al evaluated multiple such factors for their ability to stratify patients for severity or mortality. ${ }^{113}$ In addition to IL-6, lymphocyte percentage, and viral load, this study found CRP and procalcitonin to be most sensitive and reliable in separating survivors from non-survivors. Lymphocyte percentage was most sensitive at discriminating the full spectrum of severity and outcomes. Majure et al further showed that hospitalized patients with COVID-19 with elevated troponin have a greatly increased risk of mortality. ${ }^{114}$ For information on even more clinical tests in this disease, a review of 72 studies of clinical laboratory markers for their ability to predict COVID-19 disease severity and outcome is given here. ${ }^{115}$ Interestingly, some systemic inflammatory markers remain elevated 40-60 days postinfection, even in mild or asymptomatic patients. ${ }^{116}$

Autoantibodies have recently been associated with COVID-19, including antibodies to phospholipids and phospholipid-binding proteins, ${ }^{117}{ }^{118}$ antibodies to dsDNA and other specificities associated with systemic autoimmune diseases, ${ }^{119}$ and the already-mentioned antibodies to IFN ${ }^{70}{ }^{70}$ Furthermore, Woodruff $e t$ al ${ }^{120}$ found that severe COVID-19 was associated with extrafollicular B cell development, oligoclonality, and autoimmune clonotypes that were also seen in systemic lupus erythematosus patients. Together, these studies suggest autoimmune features to be a frequent occurrence in severe cases of COVID-19.

SARS-CoV-2 viral load is another clinical parameter that can be monitored. Viral load can be quantitated in plasma, which is positive in a minority of hospitalized patients and rarely in non-hospitalized patients. Fajnzylber $e t a l^{8}$ found that plasma viremia was associated with disease severity and with mortality. Zheng et $a l^{121}$ also identified SARS-CoV-2 RNA in stool, as well as serum and respiratory samples. They showed a longer duration of virus positivity in all sample types with severe disease.

\section{Sex differences}

Males tend to have worse COVID-19 outcomes than females, and this may be due in part to immunological differences. For example, males tend to have more robust production of innate cytokines and non-classical monocytes; while females have more robust $\mathrm{T}$ cell responses. ${ }^{122}$ Interestingly, poor $\mathrm{T}$ cell responses were associated with worse outcomes in male patients, but not females; while innate cytokines were correlated with worse outcomes in females but not males. ${ }^{122}$ Thus, some of the immune correlates of disease severity may in fact be sex-specific, meaning that clinical decisions based on these tests need to factor in the patient's sex.

\section{Biomarkers of long COVID-19, MIS-C, or organ damage}

The ability to predict and hopefully intervene to prevent development of 'long COVID-19' in adults or MIS-C in children would be highly useful. Elevated inflammatory markers and cytotoxicity genes, as well as autoantibodies, have been seen in MIS-C ${ }^{123}$ and some of these may be found to be predictive factors. The U.S. Tri-State Pediatric COVID-19 Research Consortium found that nonHispanic Black children were over-represented among MIS-C relative to respiratory disease cases. This consortium further found that low absolute lymphocyte count and high CRP were predictors of severe MIS-C. I am as yet unaware of similar studies to find immune predictors of patients who will develop 'long COVID-19' or postacute COVID-19 syndromes. Similarly, prediction of specific organ damage in patients with COVID-19 has so far been limited to acute monitoring of markers of tissue injury (eg, cardiac troponin I and N-terminal pro-brain natriuretic peptide for cardiac damage). And coagulopathies are monitored only by coagulation-specific markers such as D-dimer. ${ }^{124}$

\section{Current and future clinical monitoring studies}

Large longitudinal studies such as IMPACC (https:/ / www. niaid.nih.gov/clinical-trials/immunophenotyping-assessment-covid-19-cohort-impacc) and similar cohort studies in Europe, Australia, and Africa will soon provide a wealth of viral and immune monitoring data on patients treated in those regions of the world. For children, COVID-19: Pediatric Research Immune Network on SARS-CoV-2 and MIS-C study https://clinicaltrials.gov/ct2/show/ NCT04588363) will immunophenotype MIS-C samples to better understand this rare complication of pediatric COVID-19. With standardized methods, these studies could help to uncover geographical and other factors related to disease severity and sequelae, as well as provide corroborative data across different populations. Also of interest would be studies that could identify biomarkers of susceptibility and severity of COVID-19 in healthy individuals prior to infection, a more difficult area of study that is as of yet largely unexplored.

\section{CONCLUSIONS}

The literature on immunity to SARS-CoV-2 is already so vast that it cannot be comprehensively cited in a single review. Still, the studies highlighted here point to aberrations of both innate and acquired immunity in the setting of severe or fatal COVID-19. In blood, these include elaboration of high levels of IL-6 and other proinflammatory cytokines; proliferation of neutrophils (and developing neutrophils); reduction of lymphocytes, especially CD8+ $\mathrm{T}$ cells; strong elevation of plasmablasts; development of HLA-DR ${ }^{\text {low }}$ monocytes and decrease of non-classical monocytes; appearance of MDSCs; decreases in frequency and function of pDCs; and numerous changes in other immune cell subsets and their phenotypes (table 1). While virus-specific antibodies and $\mathrm{T}$ cells are produced 


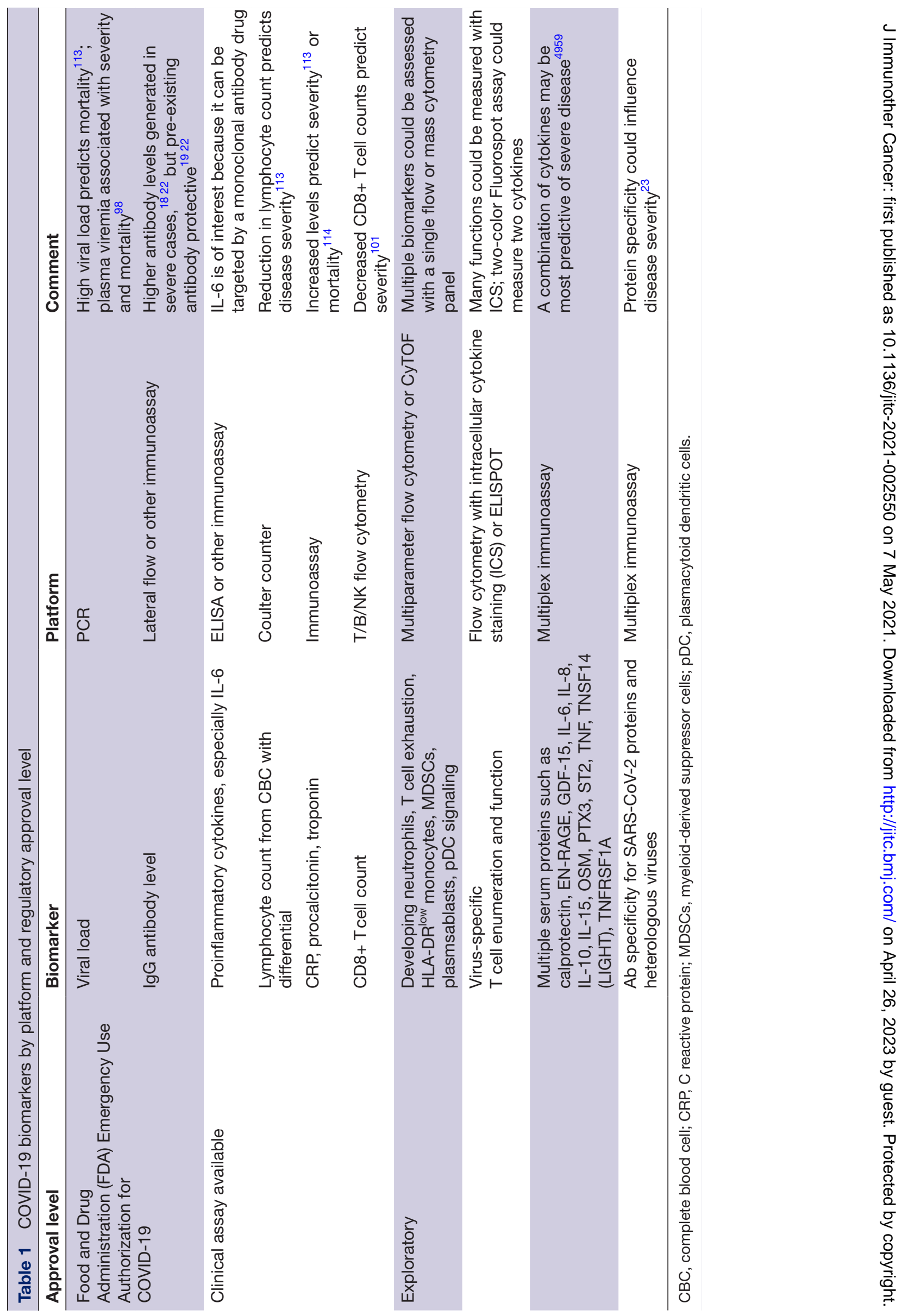


in the vast majority of cases, the clonality and epitope specificity of these adaptive responses may provide clues to the disease course. In addition, clinical tests for soluble factors such as CRP, procalcitonin, and troponin can help inform the trajectory of disease. These, along with CBC and/or TBNK flow cytometry are readily accessible to clinicians currently, and they should be used to identify patients needing the most careful monitoring and early intervention. More sophisticated tests may eventually also find clinical utility, especially if they can discriminate patients who develop particular symptoms and sequelae, or if they identify individuals at risk of worse outcomes even prior to infection or vaccination.

\section{Contributors HTM wrote and edited the manuscript.}

Funding The authors have not declared a specific grant for this research from any funding agency in the public, commercial or not-for-profit sectors.

Competing interests No, there are no competing interests.

Patient consent for publication Not required.

Provenance and peer review Not commissioned; externally peer reviewed.

Open access This is an open access article distributed in accordance with the Creative Commons Attribution Non Commercial (CC BY-NC 4.0) license, which permits others to distribute, remix, adapt, build upon this work non-commercially, and license their derivative works on different terms, provided the original work is properly cited, appropriate credit is given, any changes made indicated, and the use is non-commercial. See http://creativecommons.org/licenses/by-nc/4.0/.

\section{REFERENCES}

$1 \mathrm{Hu}$ Y, Sun J, Dai Z, et al. Prevalence and severity of corona virus disease 2019 (COVID-19): a systematic review and meta-analysis. J Clin Virol 2020;127:104371.

2 Zhu J, Ji P, Pang J, et al. Clinical characteristics of 3062 COVID-19 patients: a meta-analysis. J Med Virol 2020;92:1902-14.

$3 \mathrm{He} \mathrm{W,} \mathrm{Yi} \mathrm{GY,} \mathrm{Zhu} \mathrm{Y.} \mathrm{Estimation} \mathrm{of} \mathrm{the} \mathrm{basic} \mathrm{reproduction} \mathrm{number,}$ average incubation time, asymptomatic infection rate, and case fatality rate for COVID-19: Meta-analysis and sensitivity analysis. $J$ Med Virol 2020;92:2543-50.

4 Gavriatopoulou M, Korompoki E, Fotiou D, et al. OrganSpecific manifestations of COVID-19 infection. Clin Exp Med 2020;20:493-506.

5 Amenta EM, Spallone A, Rodriguez-Barradas MC, et al. Postacute COVID-19: an overview and approach to classification. Open Forum Infect Dis 2020;7: ofaa509.

6 Aronoff SC, Hall A, Del Vecchio MT. The natural history of severe acute respiratory syndrome coronavirus 2-related multisystem inflammatory syndrome in children: a systematic review. J Pediatric Infect Dis Soc 2020;9:746-51.

7 Rowley AH. Understanding SARS-CoV-2-related multisystem inflammatory syndrome in children. Nat Rev Immunol 2020;20:453-4.

8 Chen Y, Klein SL, Garibaldi BT, et al. Aging in COVID-19: vulnerability, immunity and intervention. Ageing Res Rev 2021;65:101205.

9 Salzberger B, Buder F, Lampl B, et al. Epidemiology of SARSCoV-2. Infection 2021;49:233-9.

10 Korber B, Fischer WM, Gnanakaran S, et al. Tracking changes in SARS-CoV-2 spike: evidence that D614G increases infectivity of the COVID-19 virus. Cell 2020;182:812-27.

$11 \mathrm{Li} \mathrm{Q}, \mathrm{Wu}$ J, Nie J, et al. The impact of mutations in SARS-CoV-2 spike on viral infectivity and antigenicity. Cell 2020;182:1284-94.

12 Hussain M, Jabeen N, Raza F, et al. Structural variations in human ACE2 may influence its binding with SARS-CoV-2 spike protein. $J$ Med Virol 2020;92:1580-6.

13 Choudhary S, Sreenivasulu K, Mitra P, et al. Role of genetic variants and gene expression in the susceptibility and severity of COVID-19. Ann Lab Med 2021;41:129-38

14 Anastassopoulou C, Gkizarioti Z, Patrinos GP, et al. Human genetic factors associated with susceptibility to SARS-CoV-2 infection and COVID-19 disease severity. Hum Genomics 2020;14:40.
15 Zhang Q, Bastard P, Liu Z, et al. Inborn errors of type I IFN immunity in patients with life-threatening COVID-19. Science 2020;370:eabd4570.

16 Wauters E, Van Mol P, Garg AD. Discriminating mild from critical COVID-19 by innate and adaptive immune single-cell profiling of bronchoalveolar lavages. Cell Res 2021;0:1-19.

17 Chua RL, Lukassen S, Trump S, et al. COVID-19 severity correlates with airway epithelium-immune cell interactions identified by singlecell analysis. Nat Biotechnol 2020;38:970-9.

18 Galipeau Y, Greig M, Liu G, et al. Humoral responses and serological assays in SARS-CoV-2 infections. Front Immunol 2020;11:610688.

19 Shrock E, Fujimura E, Kula T, et al. Viral epitope profiling of COVID-19 patients reveals cross-reactivity and correlates of severity. Science 2020;370. doi:10.1126/science.abd4250. [Epub ahead of print: 2711 2020].

20 de Assis RR, Jain A, Nakajima R, et al. Analysis of SARS-CoV-2 antibodies in COVID-19 convalescent blood using a coronavirus antigen microarray. Nat Commun 2021;12:6.

21 Crawford KHD, Eguia R, Dingens AS, et al. Protocol and reagents for pseudotyping lentiviral particles with SARS-CoV-2 spike protein for neutralization assays. Viruses 2020;12:513.

22 KW N, Faulkner N, Cornish GH. Preexisting and de novo humoral immunity to SARS-CoV-2 in humans. Science 2020;370:1339-43.

23 Sun B, Feng Y, Mo X, et al. Kinetics of SARS-CoV-2 specific IgM and IgG responses in COVID-19 patients. Emerg Microbes Infect 2020;9:940-8.

24 Gudbjartsson DF, Norddahl GL, Melsted P, et al. Humoral immune response to SARS-CoV-2 in Iceland. N Engl J Med 2020;383:1724-34.

25 Wajnberg A, Amanat F, Firpo A, et al. Robust neutralizing antibodies to SARS-CoV-2 infection persist for months. Science 2020;370:1227-30.

26 Wang K, Long Q-X, Deng H-J, et al. Longitudinal dynamics of the neutralizing antibody response to SARS-CoV-2 infection. Clin Infect Dis 2020:ciaa1143.

27 Dan JM, Mateus J, Kato Y, et al. Immunological memory to SARS-CoV-2 assessed for up to 8 months after infection. Science 2021;371:eabf4063.

28 Ward H, Cooke G, Atchison CJ. Declining prevalence of antibody positivity to SARS-CoV-2: a community study of 365.000 adults. medRxiv 2020.

29 Duysburgh E, Mortgat L, Barbezange C, et al. Persistence of IgG response to SARS-CoV-2. Lancet Infect Dis 2021;21:163-4.

30 Sakharkar M, Rappazzo CG, Wieland-Alter WF, et al. Prolonged evolution of the human B cell response to SARS-CoV-2 infection. Sci Immunol 2021;6:eabg6916.

31 Rodda LB, Netland J, Shehata L, et al. Functional SARS-CoV2-Specific immune memory persists after mild COVID-19. Cell 2021;184:169-83.

32 Gaebler C, Wang Z, Lorenzi JCC, et al. Evolution of antibody immunity to SARS-CoV-2. Nature 2021;591:639-44.

33 Edridge AWD, Kaczorowska J, Hoste ACR, et al. Seasona coronavirus protective immunity is short-lasting. Nat Med 2020;26:1691-3.

34 Kaneko N, Kuo H-H, Boucau J, et al. Loss of Bcl-6-Expressing T follicular helper cells and germinal centers in COVID-19. Cell 2020;183:143-57

35 Cagigi A, Yu M, Falck-Jones S. Airway antibodies wane rapidly after COVID-19 but $B$ cell memory is generated across disease severity. medRxiv 2020.

36 Widge AT, Rouphael NG, Jackson LA, et al. Durability of responses after SARS-CoV-2 mRNA-1273 vaccination. N Engl J Med Overseas Ed 2021;384:80-2.

37 Le Bert N, Tan AT, Kunasegaran K, et al. SARS-CoV-2-specific T cell immunity in cases of COVID-19 and SARS, and uninfected controls. Nature 2020;584:457-62.

38 Weisberg SP, Connors TJ, Zhu Y, et al. Distinct antibody responses to SARS-CoV-2 in children and adults across the COVID-19 clinical spectrum. Nat Immunol 2021;22:25-31.

39 Reche PA. Potential cross-reactive immunity to SARS-CoV-2 from common human pathogens and vaccines. Front Immunol 2020;11:586984.

40 Kadambari S, Klenerman P, Pollard AJ. Why the elderly appear to be more severely affected by COVID -19 : The potential role of immunosenescence and CMV. Rev Med Virol 2020;30:e2144.

41 Patwardhan A, Ohler A. The flu vaccination may have a protective effect on the course of COVID-19 in the pediatric population: when does severe acute respiratory syndrome coronavirus 2 (SARSCoV-2) meet influenza? Cureus 2021;13:e12533. 
42 Assarsson E, Lundberg M, Holmquist G, et al. Homogenous 96plex pea immunoassay exhibiting high sensitivity, specificity, and excellent scalability. PLoS One 2014;9:e95192.

43 Su Y, Chen D, Yuan D, et al. Multi-Omics resolves a sharp Disease-State shift between mild and moderate COVID-19. Cell 2020;183:1479-95.

44 Pietzner M, Wheeler E, Carrasco-Zanini J, et al. Genetic architecture of host proteins involved in SARS-CoV-2 infection. Nat Commun 2020;11:6397.

45 Ragab D, Salah Eldin H, Taeimah M, et al. The COVID-19 cytokine storm; what we know so far. Front Immunol 2020;11:1446.

46 Tang L, Yin Z, Hu Y, et al. Controlling cytokine storm is vital in COVID-19. Front Immunol 2020;11:570993.

47 Wilson JG, Simpson LJ, Ferreira A-M, et al. Cytokine profile in plasma of severe COVID-19 does not differ from ARDS and sepsis. JCl Insight 2020;5.

48 Sinha P, Matthay MA, Calfee CS. Is a "Cytokine Storm" Relevant to COVID-19? JAMA Intern Med 2020;180:1152-4.

49 Del Valle DM, Kim-Schulze S, Huang $\mathrm{H}-\mathrm{H}$, et al. An inflammatory cytokine signature predicts COVID-19 severity and survival. Nat Med 2020;26:1636-43.

50 Myhre PL, Prebensen C, Strand H, et al. Growth differentiation factor 15 provides prognostic information superior to established cardiovascular and inflammatory biomarkers in unselected patients hospitalized with COVID-19. Circulation 2020;142:2128-37

51 Arunachalam PS, Wimmers F, Mok CKP, et al. Systems biological assessment of immunity to mild versus severe COVID-19 infection in humans. Science 2020;369:1210-20.

52 Temesgen Z, Assi M, Shweta FNU, et al. Gm-Csf neutralization with Lenzilumab in severe COVID-19 pneumonia. Mayo Clin Proc 2020;95:2382-94

53 De Luca G, Cavalli G, Campochiaro C, et al Gm-Csf blockade with mavrilimumab in severe COVID-19 pneumonia and systemic hyperinflammation: a single-centre, prospective cohort study. The Lancet Rheumatology 2020;2:e465-73.

54 Cavalli G, De Luca G, Campochiaro C, et al. Interleukin-1 blockade with high-dose anakinra in patients with COVID-19, acute respiratory distress syndrome, and hyperinflammation: a retrospective cohort study. The Lancet Rheumatology 2020:2:e325-31.

55 Zhao Y, Kilian C, Turner J-E, et al. Clonal expansion and activation of tissue-resident memory-like Th17 cells expressing GM-CSF in the lungs of severe COVID-19 patients. Sci Immunol 2021;6. doi:10.1126/sciimmunol.abf6692. [Epub ahead of print: 2302 2021]

56 Brunetta E, Folci M, Bottazzi B, et al. Macrophage expression and prognostic significance of the long pentraxin PTX3 in COVID-19. Nat Immunol 2021;22:19-24.

57 Silvin A, Chapuis N, Dunsmore G, et al. Elevated calprotectin and abnormal myeloid cell subsets discriminate severe from mild COVID-19. Cell 2020;182:1401-18.

58 Ren X, Wen W, Fan X, et al. COVID-19 immune features revealed by a large-scale single-cell transcriptome atlas. Cell 2021:184:1895-913.

59 Abers MS, Delmonte OM, Ricotta EE, et al. An immune-based biomarker signature is associated with mortality in COVID-19 patients. JCl Insight 2021;6.

60 Nettey L, Giles AJ, Chattopadhyay PK. OMIP-050: a 28-color/30parameter fluorescence flow cytometry panel to Enumerate and characterize cells expressing a wide array of immune checkpoint molecules. Cytometry 2018;93:1094-6.

61 Sahaf B, Rahman A, Maecker HT, et al. High-Parameter immune profiling with CyTOF. Methods Mol Biol 2020;2055:351-68

62 Geanon D, Lee B, Gonzalez-Kozlova E, et al. A streamlined whole blood CyTOF workflow defines a circulating immune cell signature of COVID -19. Cytometry 2021;26.

63 Stoeckius M, Hafemeister C, Stephenson W, et al. Simultaneous epitope and transcriptome measurement in single cells. Nat Methods 2017;14:865-8

64 Netea MG, Domínguez-Andrés J, Barreiro LB, et al. Defining trained immunity and its role in health and disease. Nat Rev Immunol 2020;20:375-88.

65 O'Neill LAJ, Netea MG. Bcg-Induced trained immunity: can it offer protection against COVID-19? Nat Rev Immunol 2020;20:335-7.

66 Mantovani A, Netea MG. Trained innate immunity, epigenetics, and Covid-19. N Engl J Med 2020;383:1078-80.

67 Schulte-Schrepping J, Reusch N, Paclik D, et al. Severe COVID-19 is marked by a dysregulated myeloid cell compartment. Cell 2020;182:1419-40.

68 Kuri-Cervantes L, Pampena MB, Meng W, et al. Comprehensive mapping of immune perturbations associated with severe
COVID-19. Sci Immunol 2020;5. doi:10.1126/sciimmunol.abd7114. [Epub ahead of print: 1507 2020].

69 Lee JS, Park S, Jeong HW, et al. Immunophenotyping of COVID-19 and influenza highlights the role of type I interferons in development of severe COVID-19. Sci Immunol 2020;5:eabd1554.

70 Bastard P, Rosen LB, Zhang Q, et al. Autoantibodies against type I IFNs in patients with life-threatening COVID-19. Science 2020;370:eabd4585.

71 Falck-Jones S, Vangeti S, Yu M, et al. Functional monocytic myeloid-derived suppressor cells increase in blood but not airways and predict COVID-19 severity. J Clin Invest 2021;131. doi:10.1172/ JCl144734. [Epub ahead of print: 1503 2021].

72 Mann ER, Menon M, Knight SB, et al. Longitudinal immune profiling reveals key myeloid signatures associated with COVID-19. Sci. Immunol. 2020;5:eabd6197.

73 Laing AG, Lorenc A, Del Molino Del Barrio I, et al. A dynamic COVID-19 immune signature includes associations with poor prognosis. Nat Med 2020;26:1623-35.

74 Wilk AJ, Rustagi A, Zhao NQ, et al. A single-cell atlas of the peripheral immune response in patients with severe COVID-19. Nat Med 2020;26:1070-6.

75 Maucourant C, Filipovic I, Ponzetta A, et al. Natural killer cell immunotypes related to COVID-19 disease severity. Sci Immunol 2020;5:eabd6832.

76 Deschler S, Kager J, Erber J, et al. Mucosal-Associated invariant $\mathrm{T}$ (MAIT) cells are highly activated and functionally impaired in COVID-19 patients. Viruses 2021;13:241.

77 Flament $\mathrm{H}$, Rouland M, Beaudoin L, et al. Outcome of SARS-CoV-2 infection is linked to MAIT cell activation and cytotoxicity. Nat Immunol 2021;22:322-35.

78 Glanville J, Huang $\mathrm{H}$, Nau A, et al. Identifying specificity groups in the T cell receptor repertoire. Nature 2017;547:94-8.

79 Zelba H, Worbs D, Harter J, et al. A Highly Specific Assay for the Detection of SARS-CoV-2-Reactive $\mathrm{CD}^{+}$and $\mathrm{CD}^{+} \mathrm{T}$ Cells in COVID-19 Patients. J Immunol 2021;206:580-587.

80 Peng Y, Mentzer AJ, Liu G, et al. Broad and strong memory CD4+ and CD8+ T cells induced by SARS-CoV-2 in UK convalescent individuals following COVID-19. Nat Immunol 2020;21:1336-45.

81 Kared H, Redd AD, Bloch EM, et al. SARS-CoV-2-specific CD8+ T cell responses in convalescent COVID-19 individuals. $J$ Clin Invest 2021;131. doi:10.1172/JCl145476. [Epub ahead of print: 0103 2021]

82 Law JC, Koh WH, Budylowski P, et al. Systematic examination of antigen-specific recall T cell responses to SARS-CoV-2 versus influenza virus reveals a distinct inflammatory profile. $J$ Immunol 2021:206:37-50.

83 Braun J, Loyal L, Frentsch M, et al. SARS-CoV-2-reactive T cells in healthy donors and patients with COVID-19. Nature 2020;587:270-4.

84 Grifoni A, Weiskopf D, Ramirez SI, et al. Targets of T cell responses to SARS-CoV-2 coronavirus in humans with COVID-19 disease and unexposed individuals. Cell 2020;181:1489-501.

85 Sekine T, Perez-Potti A, Rivera-Ballesteros O, et al. Robust T cell immunity in convalescent individuals with asymptomatic or mild COVID-19. Cell 2020;183:158-68.

86 Rydyznski Moderbacher C, Ramirez SI, Dan JM, et al. Antigen-Specific adaptive immunity to SARS-CoV-2 in acute COVID-19 and associations with age and disease severity. Cell 2020;183:996-1012.

87 Neidleman J, Luo X, Frouard J, et al. SARS-CoV-2-Specific T cells exhibit phenotypic features of helper function, lack of terminal differentiation, and high proliferation potential. Cell Reports Medicine 2020;1:100081.

88 Thevarajan I, Nguyen THO, Koutsakos M, et al. Breadth of concomitant immune responses prior to patient recovery: a case report of non-severe COVID-19. Nat Med 2020;26:453-5.

89 Wang Z, Yang X, Zhong J. Exposure to SARS-CoV-2 generates T-cell memory in the absence of a detectable viral infection. Nat Commun 1724;2021:12.

90 Pierce CA, Preston-Hurlburt P, Dai Y, et al. Immune responses to SARS-CoV-2 infection in hospitalized pediatric and adult patients. Sci Transl Med 2020;12:eabd5487.

91 Tan AT, Linster M, Tan CW. Early induction of functional SARSCoV-2 specific T cells associates with rapid viral clearance and mild disease in COVID-19 patients. Cell Rep 2021;108728.

92 Schultheiß C, Paschold L, Simnica D, et al. Next-Generation sequencing of $\mathrm{T}$ and $\mathrm{B}$ cell receptor repertoires from COVID-19 patients showed signatures associated with severity of disease. Immunity 2020;53:442-55.

93 Cheng MH, Zhang S, Porritt RA, et al. Superantigenic character of an insert unique to SARS-CoV-2 spike supported by skewed TCR 
repertoire in patients with hyperinflammation. Proc Natl Acad Sci U S A 2020;117:25254-62.

94 Bacher P, Rosati E, Esser D, et al. Low-Avidity CD4+ T cell responses to SARS-CoV-2 in unexposed individuals and humans with severe COVID-19. Immunity 2020;53:1258-71.

95 Paschold L, Simnica D, Willscher E, et al. SARS-CoV-2-specific antibody rearrangements in prepandemic immune repertoires of risk cohorts and patients with COVID-19. J Clin Invest 2021;131.

96 Kermali M, Khalsa RK, Pillai K, et al. The role of biomarkers in diagnosis of COVID-19 - A systematic review. Life Sci 2020;254:117788.

97 Velavan TP, Meyer CG. Mild versus severe COVID-19: laboratory markers. Int $J$ of Dis 2020;95:304-7.

98 Fajnzylber J, Regan J, Coxen K, et al. SARS-CoV-2 viral load is associated with increased disease severity and mortality. Nat Commun 2020;11:5493.

99 Rutkowska E, Kwiecień I, Kulik K, et al. Usefulness of the new hematological parameter: reactive lymphocytes RE-LYMP with flow cytometry markers of inflammation in COVID-19. Cells 2021;10:82.

100 Zhou R, To KK-W, Wong Y-C, et al. Acute SARS-CoV-2 infection impairs dendritic cell and T cell responses. Immunity 2020;53:864-77.

101 Liu L, Chen Z, Du Y, et al. Cd8+ T cells predicted the conversion of common covid-19 to severe. Sci Rep 2021;11:2169.

102 Zheng H-Y, Zhang M, Yang C-X, et al. Elevated exhaustion levels and reduced functional diversity of T cells in peripheral blood may predict severe progression in COVID-19 patients. Cell Mol Immunol 2020;17:541-3.

103 Zhang J-Y, Wang X-M, Xing X, et al. Single-Cell landscape of immunological responses in patients with COVID-19. Nat Immunol 2020;21:1107-18

104 Mazzoni A, Salvati L, Maggi L, et al. Impaired immune cell cytotoxicity in severe COVID-19 is IL-6 dependent. J Clin Invest 2020;130:4694-703.

105 Bernardes JP, Mishra N, Tran F, et al. Longitudinal multi-omics analyses identify responses of megakaryocytes, erythroid cells, and Plasmablasts as hallmarks of severe COVID-19. Immunity 2020;53:1296-314.

106 Newell KL, Clemmer DC, Cox JB, et al. Switched and unswitched memory B cells detected during SARS-CoV-2 convalescence correlate with limited symptom duration. PLoS One 2021;16:e0244855

107 Kulkarni-Munje A, Palkar S, Shrivastava S, et al. Disease-duration based comparison of subsets of immune cells in SARS CoV2 infected patients presenting with mild or severe symptoms identifies prognostic markers for severity. Immun Inflamm Dis 2021;583. doi:10.1002/iid3.402. [Epub ahead of print: 16 Jan 2021].

108 Mathew D, Giles JR, Baxter AE, et al. Deep immune profiling of COVID-19 patients reveals distinct immunotypes with therapeutic implications. Science 2020;369:eabc8511.
109 Lucas C, Wong P, Klein J, et al. Longitudinal analyses reveal immunological misfiring in severe COVID-19. Nature 2020;584:463-9.

110 Rodriguez L, Pekkarinen PT, Lakshmikanth T, et al. SystemsLevel Immunomonitoring from acute to recovery phase of severe COVID-19. Cell Reports Medicine 2020;1:100078.

111 Zhu L, Yang P, Zhao Y, et al. Single-Cell sequencing of peripheral mononuclear cells reveals distinct immune response landscapes of COVID-19 and influenza patients. Immunity 2020;53:685-96.

112 Subrahmanyam PB, Maecker HT. CyTOF measurement of immunocompetence across major immune cell types. Curr Protoc Cytom 2017;82:9.54.1-9.54.12.

113 Tan L, Kang X, Ji X, et al. Validation of predictors of disease severity and outcomes in COVID-19 patients: a descriptive and retrospective study. Med 2020;1:128-38.

114 Majure DT, Gruberg L, Saba SG, et al. Usefulness of elevated troponin to predict death in patients with COVID-19 and myocardial injury. Am J Cardiol 2021;138:100-6.

115 Tjendra Y, Al Mana AF, Espejo AP, et al. Predicting disease severity and outcome in COVID-19 patients: a review of multiple biomarkers. Arch Pathol Lab Med 2020;144:1465-74.

116 Doykov I, Hällqvist J, Gilmour KC, et al. 'The long tail of Covid-19' The detection of a prolonged inflammatory response after a SARSCoV-2 infection in asymptomatic and mildly affected patients. F1000Res 2020;9:1349.

117 Borghi MO, Beltagy A, Garrafa E, et al. Anti-Phospholipid antibodies in COVID-19 are different from those detectable in the antiphospholipid syndrome. Front Immunol 2020;11:584241.

118 Zuo Y, Estes SK, Ali RA, et al. Prothrombotic autoantibodies in serum from patients hospitalized with COVID-19. Sci Trans/ Med 2020;12:eabd3876.

119 Vlachoyiannopoulos PG, Magira E, Alexopoulos H, et al. Autoantibodies related to systemic autoimmune rheumatic diseases in severely ill patients with COVID-19. Ann Rheum Dis 2020;79:1661-3.

120 Woodruff MC, Ramonell RP, Nguyen DC, et al. Extrafollicular B cell responses correlate with neutralizing antibodies and morbidity in COVID-19. Nat Immunol 2020;21:1506-16.

121 Zheng S, Fan J, Yu F. Viral load dynamics and disease severity in patients infected with SARS-CoV-2 in Zhejiang Province, China, January-March 2020: retrospective cohort study. BMJ;15:m1443.

122 Takahashi T, Ellingson MK, Wong P, et al. Sex differences in immune responses that underlie COVID-19 disease outcomes. Nature 2020;588:315-20.

123 Ramaswamy A, Brodsky NN, Sumida TS. Post-Infectious inflammatory disease in MIS-C features elevated cytotoxicity signatures and autoreactivity that correlates with severity. medRxiv 2020.

124 Guzik TJ, Mohiddin SA, Dimarco A, et al. COVID-19 and the cardiovascular system: implications for risk assessment, diagnosis, and treatment options. Cardiovasc Res 2020;116:1666-87. 